\title{
The patient with inflammatory bowel disease: Who am I?
}

\author{
ABR THOMSON, MD, PHD, FRCPC, FRS, FACG
}

$\mathrm{P}$ ERHAPS THE MOST IMPORTANT aspect of epidemiological studies of inflammatory bowel disease (IBD) has been the possibility of reinforcing in the mind of the patient and his or her family that he or she is not a 'freak' or a 'psychological wreck', but rather a unique human being who has had the bad luck of developing a chronic intestinal disorder. How often have I, as a practising physician, had patients tell me "I thought I was the only person on the face of the earth with this disorder. Somehow I felt 'unclean' and when others told me that this was 'all in your head', I certainly did not feel better about myself. Once I had been diagnosed, to my surprise I found that there were in fact many people like me who had Crohn's disease or ulcerative colitis, and when I went to the first meeting of the local chapter of the Canadian Foundation for Ileitis and Colitis, I was amazed to find a roomful of people; some young people like myself, some older people like my granddad, who also were sufferers. Then, and only then, did I understand the true meaning of the term 'you are very special and you are not alone'."

Epidemiological studies may be reassuring to the patient, but such studies have also given physicians and scientists clues as to the possible cause(s) of
Crohn's disease and ulcerative colitis. Such epidemiological work has shown that there certainly is an hereditary aspect to these disorders, and that there may also be an environmental component such as smoking which may contribute to the illness. Crohn's disease is more common in women than in men and more common in people who live in cities than those who live in the countryside or in smaller communities. Thus, it is possible that there are aspects of this disease related to lifestyle which may, in time, unlock important clues. The surprising finding that IBD is more common in members of certain religious groups (Jews and Mormons) again points towards genetic and environmental factors being important. When one takes into account the educational status of individuals in these religious groups, then it would appear that it is possibly the educational level itself, rather than being a member of that particular religious group, that may be the factor which needs to be incriminated in the cause of (or at least a contributing factor to) the development of ulcerative colitis and Crohn's disease. A recent and detailed review of this topic has been published in the medical literature (1).

The age of diagnosis peaks at an earlier age than the peak prevalence (Fig-

Division of Gastroenterology, University of Alberta, Edmonton, Alberta

Correspondence and reprints: Dr ABR Thomson, Division of Gastroenterology, 519 Robert Newton Research Building, University of Alberta, Edmonton, Alberta T6G 2C2. Telephone (403) 492-6490, Fax (403) 492-7964

ure 1). This suggests that the apparent plateau of new cases of IBD (Figure 2) may represent a real phenomenon of an environmental agent affecting a young and genetically susceptible population, in which the environmental risk factor(s) are now subsiding, or in which the young susceptible patients are now growing older and contributing to the expanding pool of patients with IBD. Thus, "there may be factors in the urban industrialized milieu which cause, or predispose to, the development of IBD" (2). Chronic IBD is more common in industrialized societies, with high incidence and prevalence rates reported for the United States, the United Kingdom and Scandinavia (3). IBD occurs more frequently in females and begins in adolescence and young adulthood (4); rates may be higher in the upper socioeconomic groups, in professional and white collar workers, and in persons residing in urban areas (5). A preponderance of female to male rates has been reported in the United Kingdom $(6,7)$ but not in Texas or Illinois $(8,9)$. Studies now suggest that smoking may be a risk factor for Crohn's disease and a protective factor for ulcerative colitis $(3,10,11)$.

\section{INCIDENCE AND PREVALENCE WORLDWIDE \\ 'Incidence' signifies the number of new cases of a disease diagnosed each year, expressed on the basis of the num- ber of people in the community at potential risk. The term 'prevalence'}




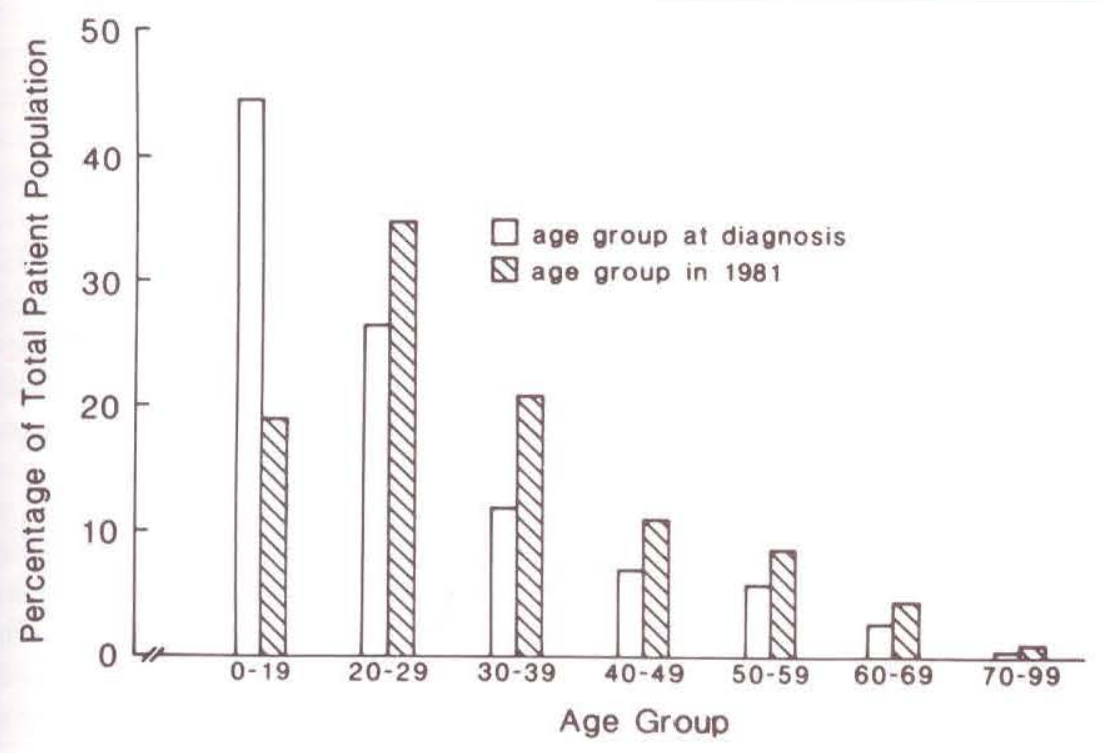

Figure 1) Age at diagnosis and at the time of survey

refers to the number of people affected with the disorder per 100,000 population. Thus, the term 'incidence' refers to the number of new cases per year whereas 'prevalence' refers to the number of sufferers from the disorder(s).

It is controversial whether the mortality rates from Crohn's disease and ulcerative colitis are increased above what might be expected in the community at large, but if the mortality rate is increased, it is only slightly so. Thus, as each year goes by and new patients are diagnosed, the prevalence will continue to rise.

Epidemiological studies may point the way towards experiments which consider diet and early childhood experiences in disease pathogenesis or disease etiology (12). In Sherbrooke, Quebec, both the incidence and prevalence of Crohn's disease are low (13) when compared with findings from many other published studies in the northern hemisphere $(12,14,15)$. High prevalence and incidence figures are generally described for western Europe and North America, with the highest figures for prevalence of Crohn's disease being 106, 75 and 56 per $10^{5}$, respectively, for the population of Olmstead County, Minnesota (16), Malmö, Sweden (17) and Cardiff, Wales (18). Both in southern and northern Alberta the incidence and prevalence of IBD is greater than in Quebec, and much greater than in other parts of the world. The reason for this is unclear. The number of new cases of Crohn's disease and ulcerative colitis appears to be increasing (Figure 2). Similar figures have been described for southern Alberta. In most areas of the world, the prevalence of ulcerative colitis is greater than Crohn's disease; that is not the case for western Canada where the prevalence is greater for Crohn's disease than for ulcerative colitis ( 44.0 versus 37.2 per $10^{5}$, respectively), where the prevalence is greater in females than in males and in those individuals living in urban rather than rural areas (64.5 versus 37.1 per $10^{5}$, respectively). For either gender or place of residence, peak prevalence is in young individuals (Figure 3). Thus, Crohn's disease is much more prevalent in, for example, young women living in Edmonton than those living in a smaller city or in the countryside (Table 1).

\section{CROHN'S DISEASE AND ULCERATIVE COLITIS - THE SAME DISEASE?}

Recent immunological studies have suggested that Crohn's disease and ulcerative colitis are not different portions of the same disease spectrum (19). Furthermore it has been recognized for

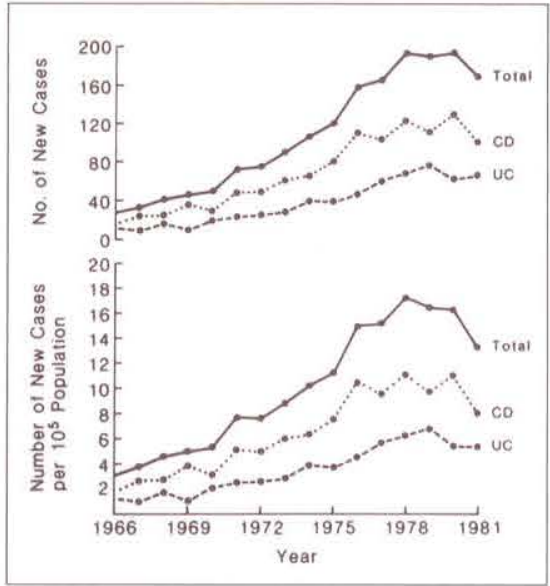

Figure 2) Top Incidence of inflammatory bowel disease in northern Alberta. Bottom Influence of year on number of patients with inflammatory bowel disease

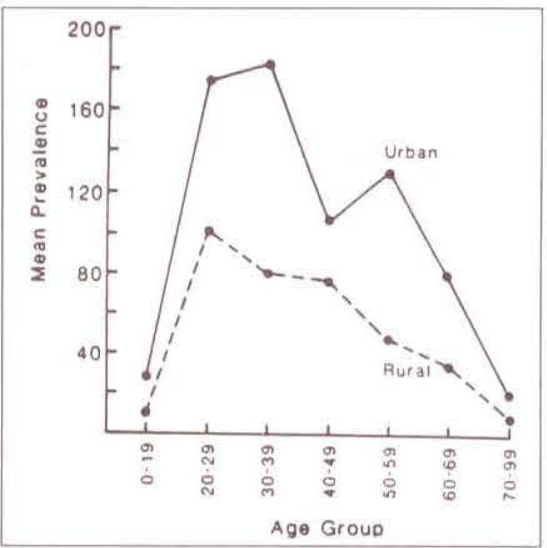

Figure 3) Influence of location of residence and age of patient on mean prevalence of Crohn's disease

many years that the two conditions may differ with regards to their radiological or pathological findings. Epidemiological studies have also suggested that these are different disorders. For example, between the ages of 20 and 69 years, there is no gender or age effect for patients with ulcerative colitis, whereas there was such an interaction for patients with Crohn's disease. Furthermore, there was no urban versus rural effect for ulcerative colitis, whereas a striking effect was seen in patients with Crohn's disease.

\section{REASONS FOR HIGH PREVALENCE IN CANADA}

The age-related factors in Crohn's disease but not in ulcerative colitis might include: early life experiences 
TABLE 1

Mean disease prevalence for diagnosis by demographic factor interactions

\begin{tabular}{|c|c|c|}
\hline \multirow[b]{2}{*}{ Factor interaction } & \multicolumn{2}{|c|}{$\begin{array}{l}\text { Prevalence per } 100,000 \text { population } \\
\text { (number of patients per cell in parentheses) }\end{array}$} \\
\hline & Crohn's disease & Ulcerative colitis \\
\hline \multicolumn{3}{|l|}{ Location and sex } \\
\hline \multicolumn{3}{|l|}{ Urban } \\
\hline Male & $63.4(331)$ & $56.5(236)$ \\
\hline Female & $95.7(493)$ & $45.0(186)$ \\
\hline \multicolumn{3}{|l|}{ Rural } \\
\hline Male & $25.4(106)$ & $38.1(109)$ \\
\hline Female & $53.4(171)$ & $33.2(84)$ \\
\hline \multicolumn{3}{|c|}{ Location and age group } \\
\hline \multicolumn{3}{|c|}{ Urban } \\
\hline 0 to 19 & $27.2(76)$ & $9.3(25)$ \\
\hline 20 to 29 & $175.1(309)$ & $70.3(126)$ \\
\hline 30 to 39 & $184.5(224)$ & $92.6(111)$ \\
\hline 40 to 49 & $112.4(87)$ & $84.9(66)$ \\
\hline 50 to 59 & $130.2(81)$ & $68.5(42)$ \\
\hline 60 to 69 & $79.5(32)$ & $92.8(37)$ \\
\hline 70 to 99 & $19.9(15)$ & $26.5(15)$ \\
\hline \multicolumn{3}{|l|}{ Rural } \\
\hline 0 to 19 & $14.2(32)$ & $8.5(20)$ \\
\hline 20 to 29 & $102.2(101)$ & $55.1(49)$ \\
\hline 30 to 39 & $79.6(62)$ & $49.4(36)$ \\
\hline 40 to 49 & $78.0(45)$ & 79.7 (39) \\
\hline 50 to 59 & $47.8(19)$ & $65.7(26)$ \\
\hline 60 to 69 & $33.5(12)$ & $76.7(20)$ \\
\hline 70 to 99 & $8.1(6)$ & $4.3(3)$ \\
\hline \multicolumn{3}{|l|}{ Sex and age group } \\
\hline \multicolumn{3}{|l|}{ Male } \\
\hline 0 to 19 & $11.9(48)$ & $9.8(24)$ \\
\hline 20 to 29 & $73.3(159)$ & $52.9(96)$ \\
\hline 30 to 39 & $65.0(109)$ & $56.0(80)$ \\
\hline 40 to 49 & $53.6(54)$ & $100.9(66)$ \\
\hline 50 to 59 & $35.5(41)$ & $78.1(36)$ \\
\hline 60 to 69 & $33.7(21)$ & $70.3(32)$ \\
\hline 70 to 99 & $5.5(5)$ & $8.8(11)$ \\
\hline \multicolumn{3}{|l|}{ Female } \\
\hline 0 to 19 & $19.7(60)$ & $7.4(21)$ \\
\hline 20 to 29 & $149.3(251)$ & 61.1 (79) \\
\hline 30 to 39 & $120.5(177)$ & $53.6(67)$ \\
\hline 40 to 49 & $111.1(78)$ & $59.8(39)$ \\
\hline 50 to 59 & 80.7 (59) & $54.0(32)$ \\
\hline 60 to 69 & $44.8(23)$ & $87.1(25)$ \\
\hline 70 to 99 & $13.7(16)$ & $5.3(7)$ \\
\hline
\end{tabular}

such as time of weaning; feeding patterns; duration of exposure to environmental substance; differences in nutrient intake; sheltered early childhood; birth order; number of siblings; size of family dwelling; or differences in the intestinal response to ageing. Patients with Crohn's disease may be weaned earlier than patients who do not develop Crohn's disease (20) but the was common, versus those who moved to other portions of northern Alberta, where the prevalence was much lower. Also, migration patterns of patients as a percentage of those patients in their present location who were born in another location was the same in Edmonton as in northern Alberta (Table $3)$. Thus, there must be one or more other factors which determine the development of Crohn's disease compared with ulcerative colitis.

The gender-related interaction effect in Crohn's disease may be due to hormonal differences between men and women, and is probably not due to the use of oral contraceptive agents (21). The possibility of female hormonal patterns being responsible for the excess of Crohn's disease in women in contrast to men is supported by the observation of the higher prevalence of Crohn's disease in women of childbearing potential.

\section{LIFESTYLES}

Smoking may be more common in patients with Crohn's disease than with ulcerative colitis (22-37) and may influence the prognosis of the disease, at least in terms of a higher risk of relapse $(29,37)$ or in terms of recurrence of Crohn's disease following surgery (38). Furthermore, smoking before the onset of symptoms is reported to be associated with an increased risk of developing Crohn's disease (39).

Smoking may be an important determinant of the type of IBD which develops in predisposed individuals (31). Thus, active and passive smoking habits may play a role in the higher prevalence of Crohn's disease than ul. cerative colitis. Numerous studies have demonstrated an association between nonsmoking and ulcerative colitis, and between smoking and Crohn's disease $(22,31)$. Indeed, the association is stronger for smoking before disease onset than for current smoking (31). Interestingly, there have been case reports of individuals with ulcerative colitis in whom the signs and symptoms of the disease disappeared when the women were smoking, but returned shortly after discontinuation of smoking $(24,25)$. But of course, if you have ulcerative colitis and you are a smoker, 
consult your doctor - there are many good reasons to stop smoking.

In Canadian studies (1) the effect of active and passive smoking on diagnosis distribution revealed that active smokers had higher rates of Crohn's disease than expected, whereas nonsmokers tended to have ulcerative colitis. Similar results were found for those individuals constantly exposed to cigarette smoke, as opposed to those who were not so exposed.

Males exposed to passive smoking did not deviate from the expected distribution of disease whereas females exhibited a higher number of Crohn's disease patients than expected. Female nonexposed patients could be expected to have a higher probability of ulcerative colitis. Young, active smokers exhibited an affinity for Crohn's disease while young nonsmokers had a higher proportion of ulcerative colitis patients. Smoking interacted with location of residence, gender and age, to influence disease prevalence and distribution.

Alcohol consumption and oral contraceptive use did not appear to influence the distribution of IBD. However, the incidence of IBD among females using oral contraceptive agents may be higher than among nonusers $(40,41)$. It is unclear why it was not possible to confirm such reports of increased risk of IBD in Albertan women using oral contraceptive agents, but it may be important to determine what was used, how long it was used, whether the woman had a family history of IBD, resided in an urban area, or smoked.

\section{RELIGIOUS AFFILIATION}

Studies conducted in Malmö (17), Nottingham (42), southeast Wales (43) and Baltimore (44) showed that members of the Jewish faith were three to 40 times more at risk of developing Crohn's disease then the overall population. The Baltimore study and a further study conducted at Stanford University (45) also found that the Jewish prevalence of ulcerative colitis was three to five times the non-Jewish prevalence. However, the prevalence of Crohn's disease is lower in Tel Aviv (46) than in European cities, but the
TABLE 2

Migration patterns of patients expressed as a percentage of those in their present location who were diagnosed in another location

\begin{tabular}{lcc}
\hline & \multicolumn{2}{c}{ Present residence } \\
Diagnosis location & Northern Alberta & Edmonton \\
\hline Maritimes & 0.6 & 1.0 \\
Quebec & 1.0 & 1.3 \\
Ontario & 2.5 & 3.5 \\
Prairies & 2.3 & 2.5 \\
British Columbia & 2.9 & 2.5 \\
United States & 0.6 & 0.6 \\
Southern Alberta & 3.3 & 3.6 \\
Northern Alberta & 85.6 & 4.2 \\
Edmonton & - & 79.1 \\
Other & 1.2 & 1.7 \\
\hline
\end{tabular}

TABLE 3

Migration patterns of patients expressed as a percentage of those patients in their present location who were born in another location

\begin{tabular}{lcc}
\hline & \multicolumn{2}{c}{ Present residence } \\
Diagnosis location & Northern Alberta & Edmonton \\
\hline Maritimes & 2.3 & 2.2 \\
Quebec & 1.8 & 2.3 \\
Ontario & 5.8 & 5.7 \\
Prairies & 13.4 & 13.9 \\
British Columbia & 4.6 & 5.6 \\
United States & 1.2 & 1.4 \\
Alberta & 60.0 & 55.4 \\
Other & 10.9 & 13.5 \\
\hline
\end{tabular}

prevalence of Crohn's disease is four times higher in the Ashkenazim community than in the Sephardim community. Most of the members of the Jewish faith residing in western Canada have immigrated from eastern Europe. A major dietary difference noted between the two groups is the preference in the Ashkenazim community for animal proteins compared with a preference in the Sephardim community for vegetable proteins.

In northern Alberta the prevalence of Crohn's disease is greater in Jewish than in non-Jewish males and the prevalence of ulcerative colitis is greater in Jewish than in non-Jewish females ( 373 versus 117 per $10^{5}$ and 194 versus 70 per $10^{5}$, respectively). The prevalence of ulcerative colitis in members of the Church of Jesus Christ of Latter Day Saints (Mormons) residing in the United Kingdom is increased (47); although the prevalence of ulcerative colitis is similar in Mormons as in nonMormons living in Alberta, the pre- valence of Crohn's disease is higher (271 versus 143 per $10^{5}$, respectively). However, when the effect of education was taken into account, this increased prevalence of IBD in Jews and Mormons was no longer evident; this suggests that it is the high educational achievement of members of these two population groups which provides the apparent increased risk of IBD, rather than any genetic or environmental factors.

The tendency for IBD patients to be better educated than the overall population has been observed in several studies $(9,44,48)$, The lack of evidence of clustering of cases in time and space $(49,50)$ argues against, but does not completely rule out, the possibility of an infectious agent (particularly one with a long latent period), or an abnormal response to a childhood infection. Analysis of age at presentation at different intestinal sites shows a unimodal distribution for small intestinal and mixed disease (small intestine and 


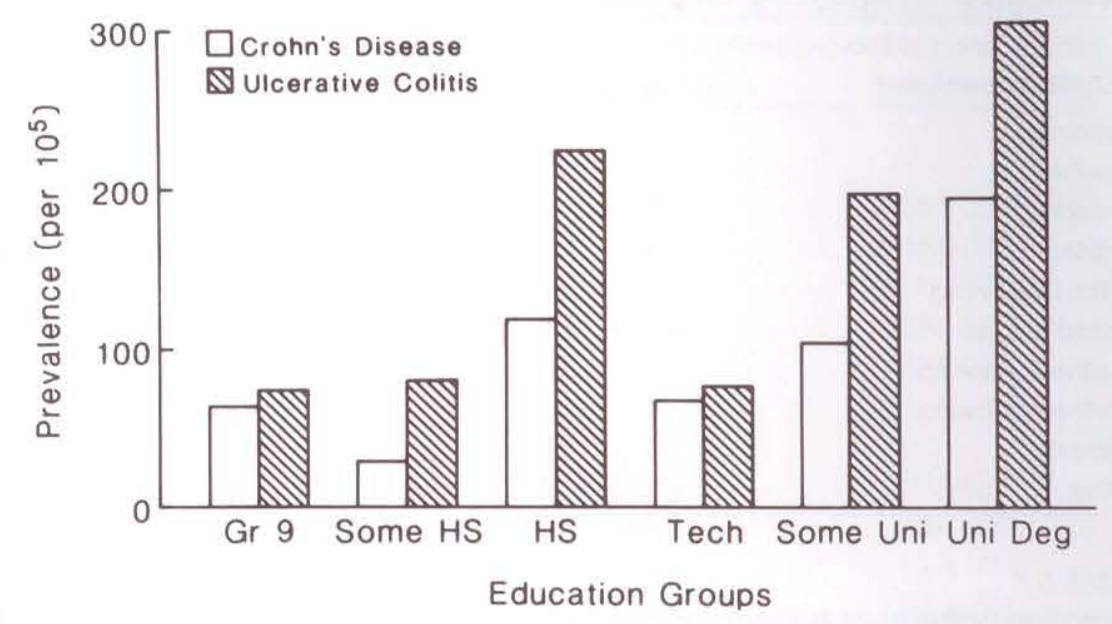

Figure 4) Effect of education on group prevalence rates of Crohn's disease and ulcerative colitis

colon), with a peak in the third to fourth decades of life (51).

\section{EDUCATION, OCCUPATION AND SOCIOECONOMIC STATUS}

The effect of socioeconomic status on the risk of developing IBD is unclear $(42,44,48,52)$. In northern Alberta, there were significant differences in prevalence between education groups, with the trend towards higher educational status (Figure 4). In those studies which have reported patients with IBD are better educated than the overall population, data have been collected from referral centres that might tend to attract more educated patients (9). The northern Alberta study was conducted in both urban and rural areas and in the community, as well as in university teaching hospitals. Also, the medicare system of the province gives all individuals equal access to health care and therefore this probably eliminated any potential bias towards reviewing only the better educated patients. Indeed, in both Crohn's disease and ulcerative colitis, the highest prevalence rates were exhibited by those people with university degrees. For example, the prevalence of Crohn's disease in individuals with a university degree was 303 per $10^{5}$ versus 80 per $10^{5}$ in those individuals with some high school education; the prevalence of ulcerative colitis in individuals with a university degree was 193 per $10^{5}$ versus 30 per $10^{5}$ in those persons with some high school education. Education has an effect on lifestyle because it affects the type of job or occupation as well as income level, and these in turn may influence lifestyle and diet.

\section{FAMILIAL PREVALENCE}

Epidemiological studies of families with members afflicted with these disorders are useful in assessing the relative risk of people with familial connections, and in the identification of trends which might point to a possible genetic involvement in the development of Crohn's disease and ulcerative colitis (18,53-60).

Previous studies have found a high prevalence of IBD among relatives, especially siblings, of patients $(18,55,61)$. There is no genetic marker for IBD, but epidemiological studies follow the pattern of polygenic inheritance (59). Early excitement with the possibility of an intestinal permeability marker for development of Crohn's disease (62) has not been reconfirmed. The lack of spousal and half-sibling involvement in familial aggregations of the disease seems to rule out the possibility that they are due just to a shared environment (53); there likely needs to be both an environmental factor(s) as well as a genetically determined predisposition.
In Alberta the presence of Crohn's disease is markedly decreased in sisters of female patients with Crohn's disease and is increased to a lesser extent in their mothers and daughters.

The common conclusion derived from the studies involving families is that genetic predisposition within the families combine with environmental and lifestyle influences to contribute to the development of $\operatorname{IBD}(53,55)$.

\section{EFFECT OF AGEING}

While it is true that IBD typically begins in early adulthood, initial onset of the illness does occur in older years and certainly as the population ages, more and more elderly patients will be seen with IBD. It is controversial whether IBD beginning in the elderly is more severe than in a young person; a variety of hospital-based and surgical series indicated that in the elderly, ul. cerative colitis often followed an aggressive, fulminant course, with a poor response to medical therapy and higher rates of toxic dilation, perforation, emergency surgery and mortality (63). Recent epidemiological reports have indicated that, independent of age, the majority of patients with ulcerative colitis have a mild illness (64-66). Other patients with Crohn's disease exhibit the entire spectrum of disease severity and complications seen in the young $(67,68)$. Some recent reports have suggested that the outlook for Crohn's disease in the elderly is not significantly different from that of younger patients $(67,69-71)$.

Recent population-based studies indicate that both ulcerative colitis and Crohn's disease in the community are less severe than has been implied by reports from major referral centres (64. 62,72-74). Epidemiological data on $\mathrm{ul}$ cerative colitis are influenced by inclusion or exclusion of patients with ulcerative proctitis, which appears to occur relatively more frequently among older than younger individuals (71). Studies addressing the subject of IBD in the elderly have generally been referring to the study of persons with the disease rather than referring to the total population of both well and diseased individuals. Complicated cases may have 
been over-represented and more accurate data on the incidence and history of IBD in elderly persons may be derived from large population-based studies.

In epidemiological surveys, the proportion of patients who develop Crohn's disease or ulcerative colitis over 60 years old averages about $16 \%$ and $12 \%$, respectively $(63)$. The incidence of ulcerative colitis among older men often exceeds that in older women $(71,74)$. Several recent epidemiological studies have found late onset Crohn's disease to be more common, with age-specific incidence rates in older patients nearly the same as, or even higher than, those for the young in some areas (75). A preponderance of women has been noted among older patients with Crohn's disease in some but not all studies $(71,75,76)$.

The majority of epidemiological studies have demonstrated a bimodal distribution in the age of onset of ulcerative colitis and Crohn's disease. The first mode occurs consistently in the third decade whereas the second varies between ages 50 and 80 years, most often near age 70. Not all epidemiological studies have confirmed this age distribution (14). If bimodality exists, it may be on the basis of two types of IBD, each having a unique age distribution and clinical characteristic but the second peak may be a different disease.

Crohn's disease involving the terminal ileum tends to affect younger patients $(52,77,78)$, regardless of whether or not the colon is also involved (79). Older patients tend to have leftsided Crohn's colitis $(52,78-81)$. Brant and co-workers (82) reviewed the clinical, roentgenological and pathological findings in 81 patients with colitis beginning after age 50 and found that three quarters of the cases likely represented ischemic colitis. Other workers, however (68), found histological evidence of ischemic damage in only $10 \%$ of their elderly patients with a diagnosis of Crohn's disease. The increased incidence of Crohn's disease is unlikely to be the result of diagnostic transfer from ulcerative colitis because the incidence of ulcerative colitis has not fallen during the same period.

In older patients the presentation of ulcerative colitis may include diarrhea, constipation or rectal bleeding; regardless of age ulcerative colitis is more likely than Crohn's disease to present in a fulminant fashion $(83,84)$. Despite a predilection for distal colitis, older patients with ulcerative colitis may be more likely than younger patients to present with severe irritable attacks (63). Toxic megacolon may occur more frequently in the elderly than in younger subjects with ulcerative colitis.

The mortality rate among patients whose ulcerative colitis begins after the age of 50 may be higher than in younger patients. However, for those who survive the first attack of ulcerative colitis without surgery, the subsequent mortality rate appears to be no greater than that of elderly persons without ulcerative colitis. The duration of the first episode of ulcerative colitis may be longer in patients over age 50 and the duration of the first remission may be shorter (85). Although more older patients have localized distal involvement, they are less likely to respond promptly to corticosteroid enemas. Indeed, in the one survey (71) patients over 60 years had a significantly better response to short term medical therapy than those under 60 . There may be a lower relapse rate in older patients with ulcerative colitis (74). In general, recent epidemiological surveys have found overall survival rates in patients with ulcerative colitis to differ little from that of the general population. $(64,66)$.

In the United States, age-specific death rates from ulcerative colitis have declined from 1962 to 1982 in all age groups, including the elderly (86).

The clinical and pathological features of Crohn's disease in the elderly differ little from those in younger patients. Perforation may occur more frequently after than before age 60 (71), and the prevalence of extraintestinal manifestations is unaffected by the age of onset $(70,71)$. Prolonged delays in diagnosis are probably more common in the elderly (70), possibly because of the tendency of distal colonic Crohn's disease to present in a more indolent fashion than ileal or ileocolonic disease $(83,87)$.
Compared with ileal Crohn's disease, Crohn's colitis affects older, predominantly female patients (83), and inflammation confined to the distal colon and rectum occurs mainly in older patients (79). Overall about onequarter to one-third of patients with Crohn's disease have involvement limited to the colon, but in the elderly this proportion often exceeds 50\% (88). The predilection of Crohn's disease in the elderly to involve the colon and the lower rate of surgery for colonic than for small intestinal Crohn's disease suggests that the need for surgery is less frequent in older patients than in younger patients. Older patients respond similarly to medical management as younger patients, and the indications for surgery in older patients with Crohn's disease are the same as those in younger persons.

Colonic disease in the elderly often responds to conservative medical management, particularly if the disease is distal or segmental in distribution $(69,89)$. Elderly individuals with Crohn's disease of recent onset appear to have a low risk of postoperative recurrence (83), although there are conflicting results (90). Mortality rates associated with Crohn's disease in the elderly are the same as or even less than the average for all patients with Crohn's disease (63), with the overall standardized mortality ratios in Crohn's disease being about twice those of the general population. Among patients who are diagnosed after age 45 , the mortality risk from Crohn's disease is no different from that of the general population nor is there any increase in operative mortality in patients undergoing surgery after age 50 (91-93).

\section{EFFECT ON THE INDIVIDUAL}

The importance of determining the impact of an illness on a patient's wellbeing, rather than simply counting the number of bowel movements or determining the hemoglobin concentration, has only recently been recognized. Several studies of therapeutic agents are now including an assessment of 'quality of life' in their assessment of possible drug efficacy. But just how disabled are IBD patients? In a survey in 
northern Alberta, IBD patients were asked to report the number of days per year which they were 'incapacitated'. The investigators were relying on the patients themselves to report the impact of the disease. Of course, some individuals might take days off work and report being 'incapacitated' where others would be more stoic and continue at school, home or in the work place. Patients with Crohn's disease reported to be incapacitated for more days than subjects with ulcerative colitis, and urban females had significantly more days incapacitated than urban males. Nonetheless, it is the very

\section{REFERENCES}

1. Pinchbeck BR, Kirdeikis J, Thomson ABR. Epidemiology of ulcerative colitis and Crohn's disease. In: Freeman HJ, ed. Inflammatory Bowel Disease, vol 1. Boca Raton: CRC Press, 1989:9-35.

2. Gilat T, Grossman A, Bujanover Y, et al. Epidemiology of inflammatory bowel disease. State of the art and etiologic inferences. In: Rachmilewitz D, ed. Inflammatory Bowel Disease. Boston: Martinus Nihjoff, 1982:143.

3. Calkins BM, Mendeloff AI. Epidemiology of inflammatory bowel disease. Epidemiol Rev 1986;8:60-91.

4. Kirsner JB, Shorter RG. Recent developments in nonspecific inflammatory bowel disease. $\mathrm{N} \mathrm{Engl}$ J Med 1982;304:837-48.

5. Grace M, Priest G. The epidemiology of inflammatory bowel disease. In: Thomson ABR, ed. Idiopathic Inflammatory Bowel Disease: Crohn's Disease and Chronic Ulcerative Colitis. Ottawa: Canadian Public Health Association Press, 1982:52-65.

6. Miller DS, Keighley AC, Langman MTS. Changing patterns of epidemiology of Crohn's disease. Lancet 1974; ii:691-3.

7. Kyle J, Stark G. Fall in the incidence of Crohn's disease. Gut 1980;21:340-3.

8. Robeson WW, Bentlif PS, Kelsey JR. Observations on 261 consecutive patients with inflammatory bowel disease seen in the southwest United States. Dig Dis Sci 1980;3:198-204.

9. Rogers BHG, Clark LM, Kirsner JB. The epidemiologic and demographic characteristics of inflammatory bowel disease: an analysis of a computerized file of 1400 patients. J Chronic Dis 1971;24:743-73.

10. Sandler RS, Golden AL. Epidemiology of Crohn's disease. J Clin Gastroenterol 1986;8:160-5.

11. Boyko EJ, Koespsell TD, Perera DR, subjectiveness of the interpretation of symptoms which leads to an individual determining that he or she is incapacitated and therefore unable to function. While patients with Crohn's disease had $60 \%$ more days per year incapacitated than did patients with ulcerative colitis, the actual average number of days was small, only 4.01 versus 2.55 per year, respectively. For the patients with Crohn's disease, the number of days incapacitated per year was greater in former heavy smokers as well as in active smokers. Of course, there will be wide variation from individual to individual, and there will be

Inui TS. Risk of ulcerative colitis among former and current cigarette smokers. N Engl J Med

1987;316:707-10.

12. Mayberry JF, Rhodes J. Epidemiological aspects of Crohn's disease: A review of the literature. Gut 1984;25:886.

13. Nootens J, Devroede G. Frequency de le'enterite regionale dans les cantons de l'est. Union Med Can 1972;101:1138.

14. Pinchbeck BR, Kirdeikis J, Thomson ABR. Inflammatory bowel disease in northern Alberta: An epidemiologic study. J Clin Gastroenterol 1988;10:505.

15. Davies F. Inflammatory bowel disease incidence and prevalence in southern Alberta. Can J Gastroenterol 1990;4:187-92.

16. Sedlack RE, Whismant J, Elveback LR, et al. Incidence of Crohn's disease in Olmstead County, Minnesota, 1935-1975. Am J Epidemiol 1980;112:759.

17. Brahme F, Lindstrom C, Wenckert A. Crohn's disease in a defined population. An epidemiological study of incidence, prevalence, mortality and secular trends in the city of Malmö, Sweden. Gastroenterology 1975;59:342.

18. Mayberry JF, Rhodes J, Newcome RG. Familial prevalence of inflammatory bowel disease in relatives of patients with Crohn's disease. Br Med J 1980;1:84-7.

19. Yacyshyn BR, Pilarski LM. Expression of CD45RO on $\mathrm{CD}_{19}{ }^{+} \mathrm{B}$ cells in Crohn's disease inversely correlates with disease status and distinguishes Crohn's disease from ulcerative colitis. Gastroenterology. (In press)

20. Bergstrand O, Hellers G. Breastfeeding during infancy in patients who later develop Crohn's disease. Scand J Gastroenterol 1983;18:903. some unfortunate persons with Crohn's disease or ulcerative colitis who will spend many months off work. Usually patients are incapacitated for only about four days a year.

It is suggested that more information needs to be obtained on this topic. However, this consideration must be taken into account when the Canadian Foundation for Ileitis and Colitis decides to become an advocate group for patients with IBD and to begin to lobby employment groups and insurance companies to provide for a fair and more reasonable basis for provision of coverage.

21. Rhodes JM, Cockel R, Allan RN, et al. Colonic Crohn's disease and use of oral contraception. Br Med J 1984;288:595.

22. Harries AD, Baird A, Rhodes J. Nonsmoking: A feature of ulcerative colitis. Br Med J 1982;284:706.

23. Bures J, Fixs B, Komarkova O, Fingerland $\mathrm{A}$. Non-smoking: $\mathrm{A}$ feature of ulcerative colitis. Br Med ] 1982;285:440.

24. de Castella H. Non-smoking: A feature of ulcerative colitis. Br Med ] 1982;284:1706.

25. Roberts CJ, Diggle R. Non-smoking: A feature of ulcerative colitis. Br Med J 1982;285:440.

26. Mayberry JF, Rhodes J, Newcombe RG. Breakfast and dietary aspects of Crohn's disease. Br Med J 1978;1:84-7.

27. Jick H, Walker AM. Cigarette smoking and ulcerative colitis. N Engl J Med 1983;308:261-3.

28. Gyde SN, Prior P, Taylor K, Allan RN. Cigarette smoking, blood pressure and ulcerative colitis. Gut 1984;24:A998.

29. Holdstock G, Savage D, Harman M, Wright R. Should patients with inflammatory bowel disease smoke? Br Med J 1984;288:362.

30. Logan RFA, Edmond M, Somerville KW, Langman MJS. Smoking and ulcerative colitis. Br Med J 1984;288:751-3.

31. Somerville KW, Logan RFA, Edmond M, Langman MJS. Crohn's disease. Br Med J 1984;289:954-6.

32. Franceschi S, Panza E, LaVecchia C, Parazzini F, Decarli A, Porro GB. Nonspecific inflammatory bowel disease and smoking. Am J Epidemiol 1987; 125:445-52.

33. Lindberg E, Tysk C, Andersson K, Jarnerot G. Smoking and inflammatory bowel disease, a case control study. Gut 1988;29:352-7.

34. Hanauer SB, Silverstein MD, Evans AA, Kirsner JB. A case control study 
of smoking in inflammatory bowel disease compared to the irritable bowel syndrome. Clin Res 1984:32:223A

35. Calkins B, Lilienfeld A, Mendeloff A, Garland F. Smoking factors in ulcerative colitis and Crohn's disease in Baltimore. Am J Epidemiol 1984;120:498. (Abst)

36. Sandler RS, Holland KL. Smoking and inflammatory bowel disease (IBD). Gastroenterology 1988;98:A398. (Abst)

37. Duffy LC, Zielezny M, Marshall J, Byers T, Weiser M, Graham S. Cigarette smoking and risk of clinical relapse in ulcerative colitis and Crohn's disease. Presented at the 1988 Annual Meeting of the Society for Epidemiologic Research, Vancouver, British Columbia, Canada. (Abst)

38. Sutherland LR, Ramcharan S, Bryant H, Fick G. Effect of cigarette smoking on recurrence of Crohn's disease. Gastroenterology 1990;98:1123-38.

39. Tobin NV, Logan RFA, Lanqman MJS, McConnell RB, Filmore IT. Cigarette smoking and inflammatory bowel disease. Gastroenterology 1987;93:316-21.

40. Lesko SM, Kaufman DW, Rosenberg $\mathrm{L}$, et al. Evidence for an increased risk of Crohn's disease in oral contraceptive users. Gastroenterology 1985;89:1046.

41. Walnut Creek Contraceptive Drug Study, 1981.

42. Keighley AC, Miller DS, Hughes AD, Langman MJS. The demographic and social characteristics of patients with Crohn's disease in the Nottingham area. Scand J Gastroenterol $1976 ; 2: 293$

43. Mayberry JF, Judd D, Smart H, Rhodes J, Calcraft B, Morris JS. Crohn's disease in Jewish people - an epidemiological study in south-east Wales. Digestion 1986;35:237-40.

44. Monk M, Mendeloff AI, Siegel CI, Lilienfeld A. An epidemiological study of ulcerative colitis and regional enteritis among adults in Baltimore. Gastroenterology 1969;56:847-57.

45. Gelpi AP. Inflammatory bowel disease among college students. West J Med 1978;129:369.

46. Rozen P, Zonis J, Yekutiel P, Gilat T. Crohn's disease in the Jewish population of Tel-Aviv-Yafo. Gastroenterology 1979;76:25-30.

47. Penny WJ, Penny E, Mayberry JF, Rhodes J. Mormons, smoking and ulcerative colitis. Lancet 1983;ii: 1315.

48. Bonnevie O. A socioeconomic study of patients with ulcerative colitis. Scand J Gastroenterol 1967;2:129-36.

49. Miller DS, Keighley AC, Smith PG, et al. Crohn's disease in Nottingham:
A search for time-space clustering. Gut 1975;16:454-7.

50. Miller DS, Keighley AC, Smith PG, et al. A case control method for seeking evidence of contagion in Crohn's disease. Gastroenterology 1976;71:385-7.

51. Lee FI, Costello FT. Crohn's disease in Blackpool - incidence and prevalence 1968-1980. Gut 1985;26:274-8.

52. Kyle J. An epidemiological study of Crohn's disease in northeast Scotland. Gastroenterology 1971;61:826.

53. Langman MJS. The Epidemiology of Chronic Intestinal Disease. London: Edward Arnold, 1979.

54. Weterman IT, Pena AS. Familial incidence of Crohn's disease in the Netherlands and a review of the literature. Gastroenterology 1984;86:449-52.

55. Singer HC, Anderson JGD, Frischer $\mathrm{H}$, Kirshner JB. Familial aspects of inflammatory bowel disease. Gastroenterology 1979;61:423-30.

56. Farmer RG, Michener WM, Mortimer EA. Studies of family history among patients with inflammatory bowel disease. Clin Gastroenterol 1980;9:271-8.

57. Lashner BA, Evans AA, Kirsner JB, Hanauer SB. Prevalence and incidence of inflammatory bowel disease in family members. Gastroenterology 1986;91:1396-1400.

58. Sategna-Guidetti C, Bianco L, Biacco E, Marucco E. Familial incidence of Crohn's disease in Italy. Dig Dis Sci 1986;31:557-8.

59. Lewkonia RM, McConnell RB. Familial IBD - heredity or environment? Gut 1976;17:235-43

60. Kirsner JB. Genetic aspects of IBD. Clin Gastroenterol 1973;2:557-75.

61. Weterman IT, Pena AS. Familial incidence of Crohn's disease in the Netherlands and a review of the literature. Gastroenterology 1984;86:449.

62. Hollander D, Vadheim CM, Brettholz E, Petersen GM, Delahunty $\mathrm{T}$, Rotter JL. Increased intestinal permeability in patients with Crohn's disease and their relatives. A possible etiologic factor. Ann Intern Med $1986 ; 105: 883$.

63. Grimm KS, Friedman LS. Inflammatory bowel disease in the elderly. In: Friedman LS, ed. Gastroenterology Clinics of North America: Gastrointestinal Disorders of the Elderly, vol 1-9. 1990:361-89.

64. Hendricksen C, Kreiner S, Binder V. Long term prognosis in ulcerative colitis - based on results from a regional patient group from the county of Copenhagen. Gut $1985 ; 26: 158$.
65. Stonnington CM, Phillips SF, Melton LJ, et al. Chronic ulcerative colitis: Incidence and prevalence in a community. Gut 1987;28:402.

66. Stonnington $\mathrm{CM}$, Phillips SF, Zinsmeister AR, et al. Prognosis of chronic ulcerative colitis in a community. Gut 1987;28:1261.

67. Gupta S. Is the pattern of inflammatory bowel disease different in the elderly? Age Aging 1985;14:366.

68. Shapiro PA, Peppercorn MA, Antonioli DA, et al. Crohn's disease in the elderly. Am J Gastroenterol 1981;76:132.

69. Fabricius PJ, Gyde SN, Shouler P. Crohn's disease in the elderly. Gut 1985;26:461,

70. Harper PC, McAuliffe TL, Beeken WL. Crohn's disease in the elderly: A statistical comparison with younger patients matched for sex and duration of disease. Arch Intern Med 1986;146:753

71. Softley A, Myren J, Clamp SE, et al. Inflammatory bowel disease in the elderly patient. Scand J Gastroenterol 1988;23(Suppl 144):27.

72. Binder V. Prognosis in Crohn's disease - based on results from a regional patient group from the county of Copenhagen. Gut 1985;26:146.

73. Gollop JH, Phillips SF, Melton LJ, et al. Epidemiologic aspects of Crohn's disease: A population based study in Olmsted County, Minnesota, 1943-1982. Gut 1988;29:49.

74. Sinclair TS, Brunt PW, Mowat NAG. Nonspecific proctocolitis in northeastern Scotland: A community study. Gastroenterology 1983;85:1.

75. Rose JDR, Roberts GM, Williams G, et al. Cardiff Crohn's disease jubilee: The incidence over 50 years. Gut 1988;29:346.

76. Tchirkow G, Lavery IC, Fazio VW. Crohn's disease in the elderly. Dis Colon Rectum 1983;26:177.

77. Fahrldnder $\mathrm{H}$, Baerlocher $\mathrm{CH}$. Clinical features and epidemiological data on Crohn's disease in the Basel area. Scand J Gastroenterol 1971;6:657.

78. Smith IS, Young S, Gillespie G, et al. Epidemiological aspects of Crohn's disease in Clydesdale, 1961-1970. Gut 1975;16:62.

79. Lockhart-Mummery HE. Crohn's disease of the large bowel. $\mathrm{Br}$ J Surg 1972;59:823.

80. Hoffman WA, Rosenberg MA. Granulomatous colitis in the elderly. Am J Gastroenterol 1972;58:508.

81. Humphreys WG. An epidemiological survey of Crohn's disease in Northern Ireland. Proc R Soc Med 1975;68:572.

82. Brandt LJ, Boley SJ, Goldberg L, et al. Colitis in the elderly: A reppraisal. 
Am J Gastroenterol 1981;76:239.

83. Cornes JS, Stetcher M. Primary Crohn's disease of the colon and rectum. Gut 1961;2:189.

84. Lennard-Jones JE, Ritchie JK, Zohrab WB. Proctocolitis and Crohn's disease of the colon: A comparison of the clinical course. Gut 1976;17:477.

85. Zimmerman J, Gavish D, Rachmilewitz D. Early and late onset ulcerative colitis: Distinct clinical features. J Clin Gastroenterol 1985; 7:492.

86. Sonnenberg A. Mortality from Crohn's disease and ulcerative colitis in England-Wales and the US from 1950 to 1983. Dis Colon Rectum 1986;29:624.

87. Ritchie JK, Lennard-Jones JE. Crohn's disease of the distal large bowel. Scand J Gastroenterol 1976;11:433.

88. Lee Fl, Giaffer M. Crohn's disease of late onset in Blackpool. Postgrad Med J 1987;63:471.

89. Elliott PR, Ritchie JK, Lennard-Jones JE. Prognosis of colonic Crohn's disease. Br Med J 1985;291:178.
90. Rusch V, Simonowitz DA. Crohn's disease in the older patient. Surg Gynecol Obstet 1980;150:184.

91. Cooke WT, Mallas E, Prior P. Crohn's disease: Course, treatment and long-term prognosis. QJ Med 1980;49:363.

92. Hellers G. Crohn's disease in Stockholm County (1955-1974). Acta Chir Scand 1979;490:1

93. Prior P, Gyde SN, Cooke WT, et al. Mortality in Crohn's disease. Gastroenterology 1981;80:307. 


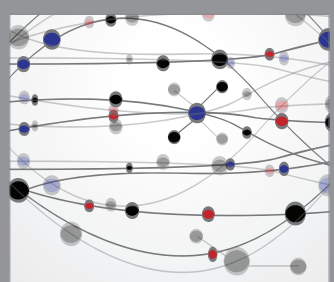

The Scientific World Journal
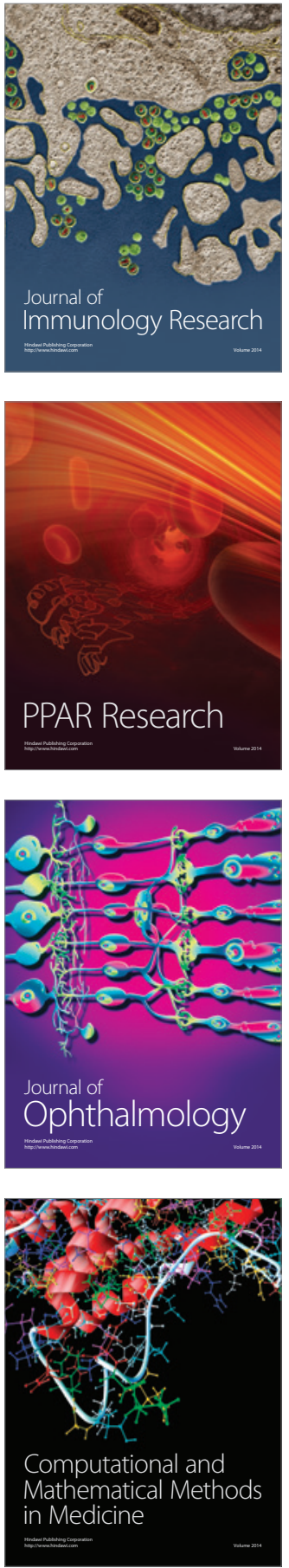

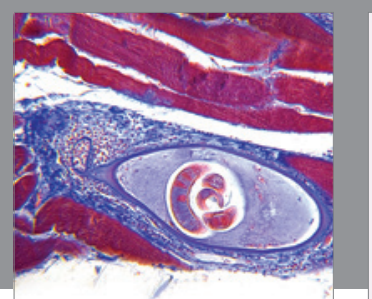

Gastroenterology Research and Practice

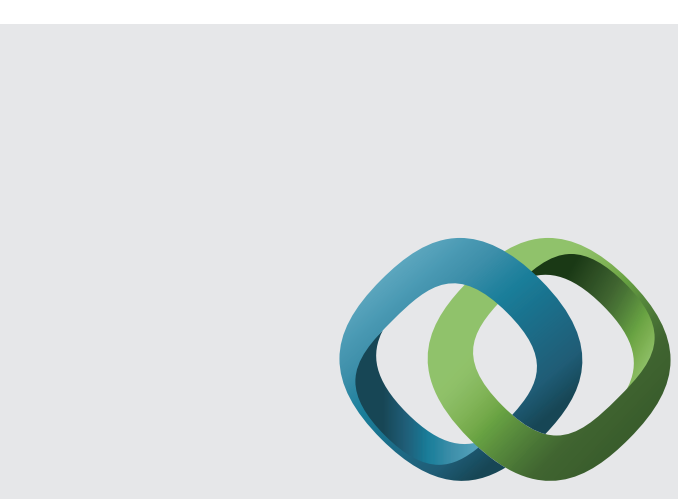

\section{Hindawi}

Submit your manuscripts at

http://www.hindawi.com
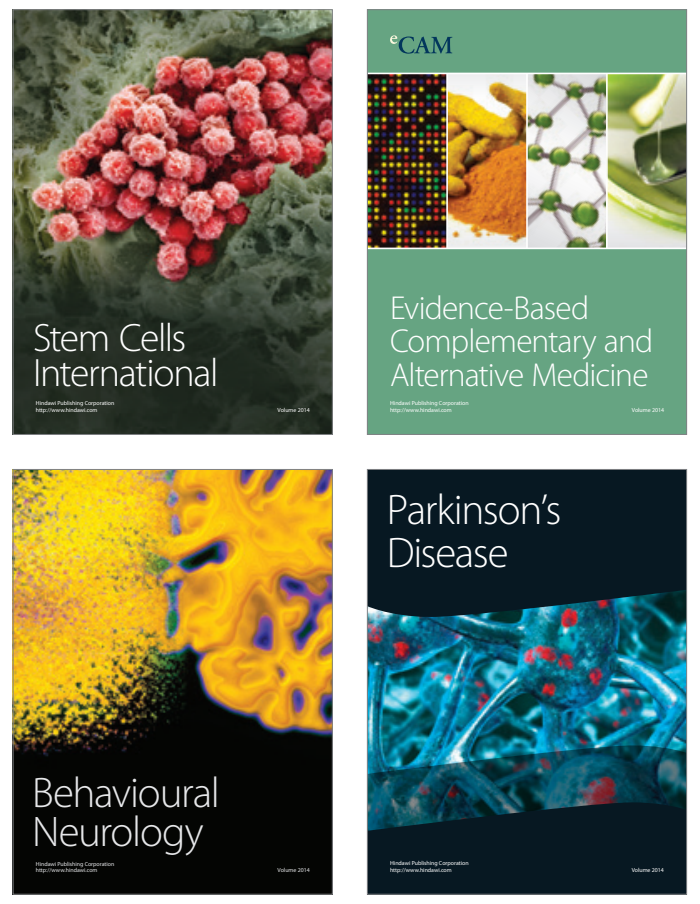
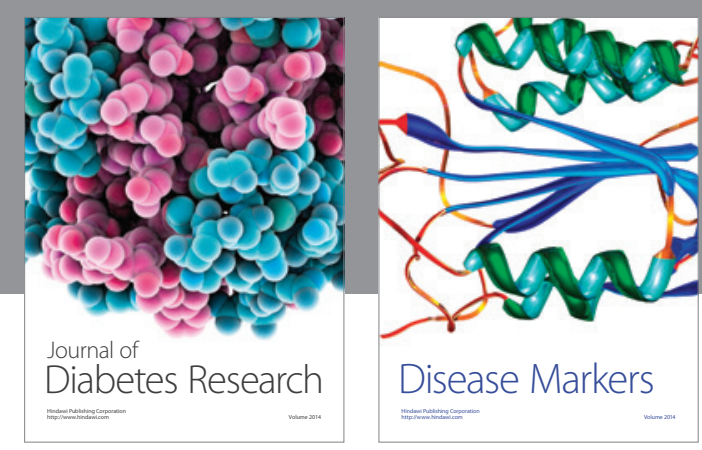

Disease Markers
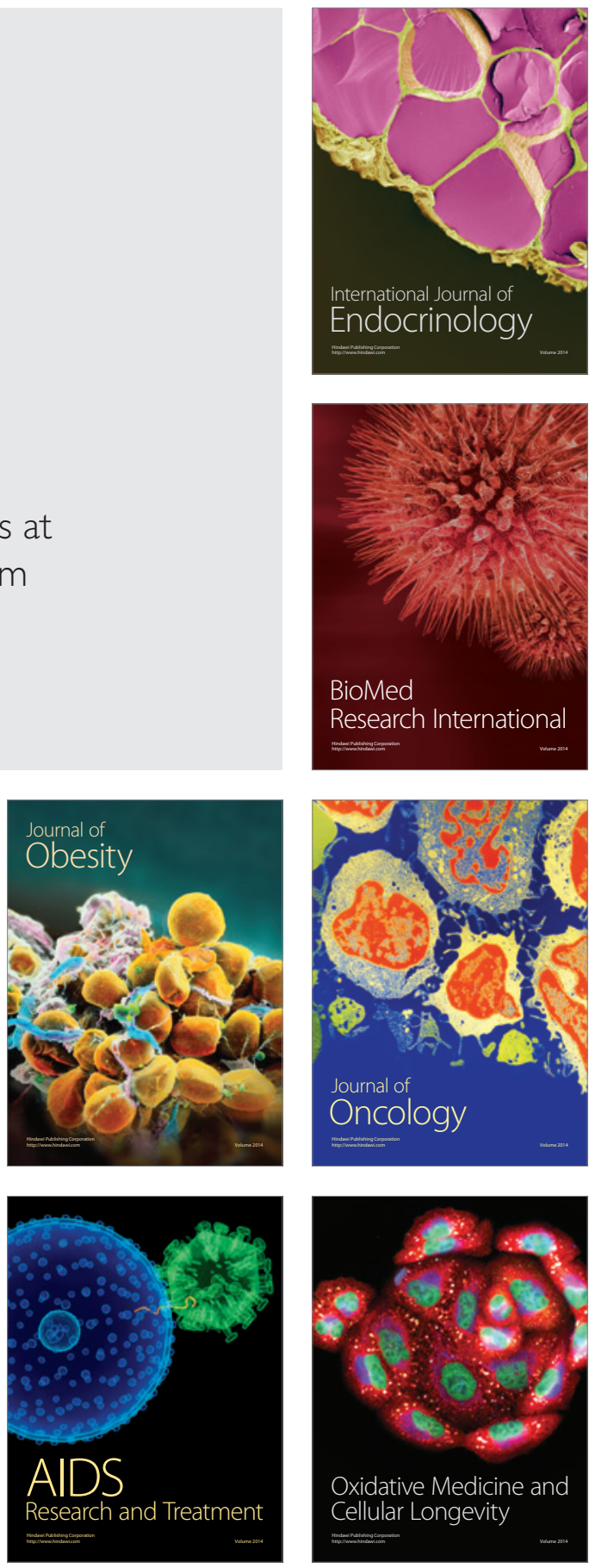